\title{
Platelet protein biomarker panel for ovarian cancer diagnosis
}

\author{
Marta Lomnytska ${ }^{1,2,3^{*}}$ (D), Rui Pinto ${ }^{4}$, Susanne Becker ${ }^{3}$, Ulla Engström $^{5}$, Sonja Gustafsson ${ }^{6}$, Christina Björklund ${ }^{6}$,

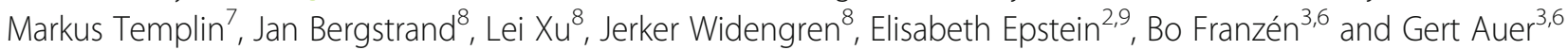

\begin{abstract}
Background: Platelets support cancer growth and spread making platelet proteins candidates in the search for biomarkers.

Methods: Two-dimensional (2D) gel electrophoresis, Partial Least Squares Discriminant Analysis (PLS-DA), Western blot, DigiWest.

Results: PLS-DA of platelet protein expression in 2D gels suggested differences between the International Federation of Gynaecology and Obstetrics (FIGO) stages III-IV of ovarian cancer, compared to benign adnexal lesions with a sensitivity of $96 \%$ and a specificity of $88 \%$. A PLS-DA-based model correctly predicted 7 out of 8 cases of FIGO stages I-II of ovarian cancer after verification by western blot. Receiver-operator curve (ROC) analysis indicated a sensitivity of $83 \%$ and specificity of $76 \%$ at cut-off $>0.5$ (area under the curve (AUC) $=0.831, p<0.0001$ ) for detecting these cases. Validation on an independent set of samples by DigiWest with PLS-DA differentiated benign adnexal lesions and ovarian cancer, FIGO stages III-IV, with a sensitivity of $70 \%$ and a specificity of $83 \%$.
\end{abstract}

Conclusion: We identified a group of platelet protein biomarker candidates that can quantify the differential expression between ovarian cancer cases as compared to benign adnexal lesions.

Keywords: Ovarian cancer, Platelet proteome, Biomarker, Liquid biopsy

\section{Background}

Epithelial ovarian cancer is characterised by an asymptomatic growth in the abdominal cavity. In $75 \%$ of all cases, it is only detected at an advanced stage. The 5-year survival rate in FIGO stages I-II is over $90 \%$, compared to around $30 \%$ in stages III-IV [1, 2]. The sensitivity of the CA-125 tumor marker for the detection of non-advanced epithelial ovarian cancer ranges from $50 \%$ to $70 \%$, and this parameter alone is not recommended for differentiating between a benign and a malignant adnexal mass [3]. An expertly conducted transvaginal sonography (TVS) is a primary method for evaluation of ovarian and pelvic tumors, as it is able to discriminate between benign and malignant conditions with $90 \%$ sensitivity and $94 \%$

\footnotetext{
* Correspondence: marta.lomnytska@gmail.com

'Department of Obstetrics and Gynaecology, Academical Uppsala University Hospital, Uppsala University, SE-751 85 Uppsala, Sweden

${ }^{2}$ Institute of Women's and Children's Health, Karolinska Institute, SE-171 76

Stockholm, Sweden

Full list of author information is available at the end of the article
}

specificity using the International Ovarian Tumor Analysis (IOTA) pattern recognition [4, 5]. Despite high performance of TVS, the assessment will be inconclusive in around $8 \%$ of cases, also in the hands of an expert examiner [4]. Commonly used tumor markers, such as CA-125, HE4 and the Risk of Malignancy Index (RMI), did not improve, but rather deteriorated assessment in these difficult to classify tumors [6].

A several-fold increase in a patient's platelet count is a common observation in cancer. A high preoperative platelet count is associated with early relapse in nonadvanced epithelial ovarian cancer [7] and colorectal cancer [8]. Platelets influence angiogenic and immunological processes in cancer $[9,10]$, as well as directly protect tumor cells [7]. Proteomic analysis of platelets has identified several potential cancer markers [11]. Among them are angiogenic factors that have been shown to be sequestered by platelets [12] and delivered to the site of activated endothelium within an early 
tumor [11]. Detection of platelet-derived growth factor, platelet factor 4 (PF-4) and platelet-derived endothelial cell growth factor was suggested for diagnosis of several cancers [13]. Upon platelet activation, PF-4, vascular endothelial growth factor (VEGF) and fibrinogen undergo significant spatial rearrangements, detectable only by super resolution stimulated emission depletion (STED) microscopy [14].

The proteome of platelets in ovarian cancer has not been previously studied. The hypothesis of the current study is that knowledge of quantitative alterations of proteins in platelets can become the basis for noninvasive diagnosis of ovarian cancer and evaluation of the malignant potential of adnexal lesions.

\section{Methods}

The study comprised three phases:

1. Platelet pellets were prospectively collected from patients with benign adnexal lesions and ovarian cancer. This clinical material was subjected to twodimensional (2D) gel electrophoresis, statistical analysis of protein expression, and subsequently, mass spectrometry-aided identification of protein biomarker candidates.

2. Antibody identification and confirmation of protein identification by western blot.

3. Verification of our biomarker candidate protein panel using western blot and DigiWest, and evaluation of sensitivity and specificity for detecting ovarian cancer.

\section{Clinical material}

Blood samples were obtained from volunteering women with adnexal lesions and suspected ovarian cancer. Approval for the study was given by the local ethical committee of Stockholm County Council, Dnr 2010/504-31. Cases were coded as "TR" followed by a number, and the coding was saved separately from the personal information of patients. Clinical material from 114 patients was prospectively collected between 2011 and 2014 at the Department of Obstetrics and Gynaecology, Karolinska University Hospital-Solna, Stockholm, Sweden (Table 1, Additional file 1: Table S1). Peripheral venous blood was drawn from the antecubital vein of each subject. The requirement for inclusion in the study was collection of a blood sample prior to any invasive diagnostic or treatment procedures. Patients with another known active cancer were excluded from the study. Patient records included age at diagnosis, comorbidities, medication with coagulation and platelet aggregation blockers, optionally - TVS according to IOTA criteria, and post-operative histopathological
Table 1 Description of the clinical material

\begin{tabular}{|c|c|c|c|c|c|}
\hline \multirow[t]{2}{*}{ Benign lesions } & \multirow[b]{2}{*}{$n$} & \multicolumn{4}{|c|}{ Epithelial ovarian cancer, C56.9 } \\
\hline & & stages I-II & $\mathrm{n}$ & stages III-IV & $n$ \\
\hline $\begin{array}{l}\text { Serous ovarian } \\
\text { cyst, N82.3 }\end{array}$ & 19 & serous & 2 & serous & 47 \\
\hline $\begin{array}{l}\text { Ovarian fibrom, } \\
\text { N82.3 }\end{array}$ & 10 & mucinous & 1 & endometrioid & 1 \\
\hline $\begin{array}{l}\text { Dermoid ovarian } \\
\text { cyst, N82.3 }\end{array}$ & 5 & endometrioid & 2 & clear-cell & 1 \\
\hline $\begin{array}{l}\text { Endometriosis cyst, } \\
\text { N80.1 }\end{array}$ & 8 & clear-cell & 3 & & \\
\hline $\begin{array}{l}\text { Mucinous ovarian } \\
\text { cyst, N83.2 }\end{array}$ & 10 & & & & \\
\hline $\begin{array}{l}\text { Non-cancer ascites, } \\
\text { R18.9 }\end{array}$ & 1 & & & & \\
\hline $\begin{array}{l}\text { Paratubar cyst, } \\
\text { Q50.5 }\end{array}$ & 2 & & & & \\
\hline $\begin{array}{l}\text { Uterine myom, } \\
\text { D25.9 }\end{array}$ & 2 & & & & \\
\hline Total & 57 & & 8 & & 49 \\
\hline
\end{tabular}

Transvaginal sonography, IOTA classification

Ultrasound Certainty in the assessment Histopathology $n$ assessment

Benign certainly benign benign 7

Benign probably benign benign 16

Benign uncertain benign 6

Borderline tumor uncertain benign 4

Malignant probably benign 2

Malignant certainly malignant $1^{\text {a }}$

Malignant certainly malignant $13^{\text {b }}$

no IOTA-based benign 22

examination

no IOTA-based malignant $\quad 7^{\mathrm{a}}$

examination

no IOTA-based malignant $36^{\mathrm{b}}$

examination

Total

Comorbidities $n$ coagulation/aggregation blockers n

None $99 \quad$ none 111

$\begin{array}{llll}\text { One or few } & 15 & \text { Warfarin } & 1\end{array}$

following diseases:

$\begin{array}{lll}\text { Breast cancer } & 4 & \text { Dabigatran } \\ \text { remission } & & 1\end{array}$

$\begin{array}{llll}\text { Cardiovascular } & 14 & \text { Aspirin } & 1\end{array}$

$\begin{array}{llll}\text { Rheumatic } & 2 & \text { Total } & 114\end{array}$

Endocrine $\quad 4 \quad$ Experimental setup, $\mathrm{n}$ 
Table 1 Description of the clinical material (Continued)

\begin{tabular}{|c|c|c|c|c|c|}
\hline \multicolumn{6}{|c|}{ Diagnosis and International classification of disease (ICD) coding } \\
\hline \multirow[t]{2}{*}{ Benign lesions } & \multirow[b]{2}{*}{$\mathrm{n}$} & \multicolumn{4}{|c|}{ Epithelial ovarian cancer, C56.9 } \\
\hline & & stages I-II & $\mathrm{n}$ & stages III-IV & $\mathrm{n}$ \\
\hline Astma & 2 & $\begin{array}{l}\text { Method/ } \\
\text { Statistics }\end{array}$ & Benign & $\begin{array}{l}\text { Ovarian cancer, } \\
\text { stage }\end{array}$ & \\
\hline Hepatitis C & 1 & & lesions & $|-| \mid$ & $\begin{array}{l}\text { III- } \\
\text { IV }\end{array}$ \\
\hline \multirow[t]{4}{*}{ Total } & 114 & 2D/PCA & 28 & 8 & 32 \\
\hline & & 2D/PLS-DA & 25 & 8 & 30 \\
\hline & & $\begin{array}{l}\text { Western } \\
\text { blot/PLS-DA }\end{array}$ & 20 & 8 & 20 \\
\hline & & $\begin{array}{l}\text { DigiWest/ } \\
\text { PLS-DA }\end{array}$ & 29 & 0 & 30 \\
\hline
\end{tabular}

astages I-II

bstages III-IV

conclusion. Randomization of the material was performed prior to experimental procedures.

\section{Isolation of platelets from peripheral blood}

Peripheral venous blood was drawn into $4.5 \mathrm{ml}$ vacutainer plastic whole blood collection tubes with spray-coated $\mathrm{K}_{2}$ EDTA (Vacutainer, BD, Franklin Lakes, NJ, USA) and processed within $30 \mathrm{~min}$. Isolation of platelets was performed by three centrifugation steps. Exclusion of erythrocytes and leucocytes was achieved by centrifugation of whole blood at 1500 relative centrifugal force (RCF) for $10 \mathrm{~min}$ at $+4{ }^{\circ} \mathrm{C}$, and the platelet-rich plasma obtained was subjected to a second centrifugation at 3000 RCF for $10 \mathrm{~min}$ at $+4{ }^{\circ} \mathrm{C}$ [15]. The resulting platelet pellet was re-suspended in $500 \mu \mathrm{L} 0.9 \% \mathrm{NaCl}$ and centrifuged at $3000 \mathrm{RCF}$ for $10 \mathrm{~min}$ at $+6{ }^{\circ} \mathrm{C}$. The quality and purity of the platelet isolation was confirmed by light microscopy after immunostaining with an antibody against CD61 (119,992, Abcam, Cambridge, UK). In addition, fluorescence-activated cell sorting (FACS) of selected cases using the antibody against p-selectin, or CD62 $(348,107$, BD Biosciences-Europe) was also used to assess quality and purity. Platelet pellets were aliquoted to avoid excess freeze-thaw cycles and stored at $-70{ }^{\circ} \mathrm{C}$.

\section{Two-dimensional gel electrophoresis}

The platelet fractions for 2D gel electrophoresis were lyophilized and resuspended in lysis buffer; the protein concentration was determined using the Bradford protein analysis protocol [16] and the Versa Max Microplate reader (Molecular Devices, Sunnyvale CA, USA). Samples of $75.0 \mu \mathrm{g}$ protein were subjected to 2D gel electrophoresis as previously described [17]. One 2D gel per clinical case was included into analysis after evaluation of the gel quality, i.e., absence of protein degradation protein spot smearing or overstraining. The expression level of protein spots in 2D gels was analysed using Progenesis SameSpot software (Nonlinear Dynamics, London, UK). The cut-off for selection of protein spots was a relative expression difference of 1.5-fold, $p<0.05$, power $>0.8, q<0.05$, as evaluated by analysis of variance (ANOVA) by the SameSpot software.

\section{Search parameters and acceptance criteria for MS/MS and peptide mass fingerprint (PMF)}

Protein spots selected for identification were excised from the gels, treated for in-gel digestion, and subjected to MALDI TOF mass spectrometry carried out on the Ultraflex III TOF/TOF (Bruker Daltonics, Bremen, Germany). Peptide spectra were internally calibrated using trypsin autolytic peptides. A peak list generating software, Data Analysis 3.2 (Bruker Daltonics, Bremen, Germany), was used. In selected cases, MS/MS was performed with acceptance score exceeding 30. Mass tolerance for fragment ions was $0.5 \mathrm{Da}$. Based on the obtained peptide spectra, identification of the proteins was performed using the MASCOT (Matrix Science, London, England) and the "NCBInr" database. The deviation of mass did not exceed 0.05 Da. Probability of identification was evaluated according to score value, sequence coverage, and matched peptides. All other steps were performed as previously described [17].

\section{Western blot analysis}

A semi-quantitative dual label fluorescent detection western blot analysis was performed using the same patient cases that were subjected to $2 \mathrm{D}$ gel electrophoresis (Table 1). Samples were diluted in $4 \times$ lithium dodecyl sulfate (LDS) buffer and $10 \times$ reducing agent to a concentration of $1 \mu \mathrm{g} / \mu \mathrm{l}$, and then incubated for $10 \mathrm{~min}$ at $70{ }^{\circ} \mathrm{C}$. Four NuPAGE $4-12 \%$ Bis-Tris Gel, $1.0 \mathrm{~mm} \times 15$ wells were run in parallel; a total of $10 \mu \mathrm{g}$ protein per case was loaded. Gel running conditions were as follows: $200 \mathrm{~V}$ for $60 \mathrm{~min}$ in XCell SureLock Mini-Cell EI0001 (Life Technologies, Stockholm, Sweden), followed by incubation of gels in transfer buffer containing $10 \%$ methanol and blotting to a nitrocellulose membrane for $1 \mathrm{~h}$ at $30 \mathrm{~V}$ (BioRad Power Pac 100 and Hoefer EPS 2A200). Membranes were incubated with Odyssey blocking buffer (Li-Cor Biosciences, East Chesterton Ward, UK) with addition of $0.1 \%$ Tween 20 for one hour, and then with the combination of commercially available primary antibodies, GAPDH and anti-14-3-3-gamma for loading controls [18] (Additional file 1: Table S2) with rotation at $+4{ }^{\circ} \mathrm{C}$ overnight. After washing with PBS, each membrane was incubated with secondary antibodies (IRDye 2nd Ab Goat anti-Rabbit 680, 1:10,000 and IRDye 2nd Ab Goat anti-Mouse 800, 1:15,000, LiCor Biosciences, East Chesterton Ward, UK) at room temperature for $1 \mathrm{~h}$. After washing with PBS, each 
membrane was scanned using the Odyssey SA Infrared Imaging System (Li-Cor Biosciences, East Chesterton Ward, UK).

\section{DigiWest analysis}

For each platelet lysate, two technical repeats $(20 \mu \mathrm{g}$ protein per lane) were subjected to SDS-PAGE using 4-12\% BisTris gradient gels. After blotting with primary antibodies (Additional file 1: Table S2) and biotinylation of the proteins, individual sample lanes were cut into 96 molecular weight fractions $(0.5 \mathrm{~mm}$ each) and proteins were eluted. Eluted proteins from each molecular weight fraction were loaded onto color-coded neutravidin-coated Luminex bead sets (MagPlex, Luminex, Austin TX, USA), and the antibody specific signals were analysed (DigiWest analysis, version 3.8.5.2, Excel-based) [19].

\section{Multivariate methods (PCA, PLS-DA, OPLS-DA)}

Principal components analysis (PCA) [20] is the most widely used (non-supervised) multivariate method, and the root to most others. By finding covariance between multiple (correlated) variables in a single dataset $\mathbf{X}$, it sequentially defines (uncorrelated, or orthogonal) principal components, with decreasing amount of variance explained, built from weighted initial variables. A number of interesting components can be selected, as variation in the dataset is reframed as structured (e.g. biological information) or residual (noise). Each component defines a percentage of variation of the original dataset, and is described by two vectors: scores, representing the score of each sample in the newly created principal component; loadings, representing the weight of each initial variable in the principal component. PCA performs dimensionality reduction, thus allowing one to condense most of the information in a large dataset into a small number of components. Its scores and loadings can be plotted and used as an exploratory technique, to find relations between variables, detect groups and trends in the samples, as well as outliers.

Projection to latent structures (PLS) is a well established (supervised) method for the analysis of complex multivariate datasets, as found in the -omics fields, including proteomics $[21,22]$. In originates from partial least squares regression, a multivariate analysis method which relates two matrices ( $\mathbf{X}$ with the actual data or independent variables, and $\mathbf{Y} / \mathbf{y}$ as responses or dependent variables) by maximizing the covariance of their latent variables. The 2-class PLS-DA is simply a particular type of PLS in which the dependent variable is a "dummy" binary $(0 / 1)$ class $\mathbf{y}$-vector. PLS-DA targets complementary objectives: as a discriminant method, it allows discrimination/prediction of class for test samples; as a multivariate method it shows the relationship among variables in the dataset through the creation of latent variables, built using weighted original variables; as a linear method, it allows one to visualize and understand which variables in the data are more relevant for the class discrimination.

Orthogonal PLS (OPLS) [23] is a modification of the PLS method, and while both models have the same model statistics and prediction capability, OPLS allows for easier interpretation of the relevant variables than PLS. The reason is because apart from dividing variation into systematic and residual (as PLS), OPLS also divides the systematic variation into predictive (related to the phenomenon in study) and orthogonal (structured variation related to other factors, such as age and gender). This property is advantageous when interpretation of the results, rather than prediction, is the main objective of the analysis. In the context of OPLS-DA the statistically significant predictive loadings show which initial variables are important in the discrimination of class, and in which class these variables have higher values.

\section{(O)PLS-DA number of latent variables and validation [24]}

(O)PLS-DA models can separate data variability into systematic and random, and use the systematic one for building the actual model while discarding the random variation, or noise. In order to attain that objective, it is critical to select an appropriate number of latent variables for the model, which is achieved in general through the use sampling methods such as cross-validation (CV). In this strategy, one calculates multiple (O)PLS-DA models using subsets of the $\mathbf{X}$ data, while predicting the class (y) of the samples left out in each round. By doing this for models with different number of latent variables, one can evaluate how well predicted by the model are the samples that were left out in each of those models, and select the best one. It yields the following cross-validation's statistics: $\mathrm{R} 2 \mathrm{X}$ - fraction of the variance in $\mathbf{X}$ explained by each latent variable; R2- fraction of variance of $\mathbf{y}$ (class) explained by each latent variable; and most importantly Q2- the fraction of variance of $\mathbf{y}$ predicted by the model. A model with good modelling and predictive power is desired, and while $\mathrm{R} 2 \mathrm{X}$ may be low (due to low number of variables in $\mathbf{X}$ explaining class discrimination), R2Y and Q2 should be the closest possible to each other, as well as close to a maximum of 1 .

After a model is built, containing the appropriate number of latent variables, it undergoes appropriate validation procedures, notably cross-validation analysis of variance (CV-ANOVA), permutation test, and evaluation of cross-validation scores. CV-ANOVA compares the $y$ predicted residuals of the model of interest with the variation around the global average using an F-test, resulting in a significance $p$-value for decisional purposes. Permutation test evaluates the statistical significance of estimated predictive power, 
by comparing R2 and Q2 of multiple models (where y was randomized) with $\mathrm{R} 2$ and $\mathrm{Q} 2$ of the actual model of interest. If the model is significant, its values are expected to be higher than for the $y$ randomized models. Cross-validation scores are scores that are calculated for each sample during cross validation, and can be visually or systematically evaluated to indicate over-fitting in case they differ from the regular scores.

\section{Prediction of test samples and variable relevance for class discrimination}

After proper choice of number of latent variables and method validation, the model can be used for prediction of test samples, and to find out which variables are relevant for class discrimination.

As class membership is defined by the $0 / 1$ dependent variable $\mathbf{y}$ vector in the training set, class membership of "new" samples in a test set is dependent on their predicted y value. Samples similar to class "1" are expected to yield values of $\mathbf{y}$ similar to 1 , thus above a certain threshold, e.g. 0.5, while samples similar to the ones in class "0" will be predicted below that threshold.

To find out which variables are relevant for class discrimination, two methods are commonly used: the variable importance on the projection (VIP) method, which is an (unsigned) compact parameter to summarize the importance of each of the variables in PLS-type models with more than one latent variable; the other method can be used with OPLS-type models and checks if the confidence interval for the mean of the CV-calculated loadings crosses zero or not (in which case it is consistently positive or negative for each of the cross validation models).

PCA, PLS-DA and OPLS-DA were performed using SIMCA P v13.0 software (Umetrics AB).

\section{Experimental design and statistical rationale}

Normalized expression values exported from SameSpot software of all protein spots (approximately 2000 spots in one 2D gel) were subjected to PCA analysis and PLS-DA.

PCA analysis was performed using the material from patients with benign adnexal lesions (28 cases), ovarian cancer, International Federation of Gynaecology and Obstetrics (FIGO) stages I-II (8 cases), and ovarian cancer, FIGO stages III-IV (32 cases) (Table 1). The PLS-DA model was based on the expression of all platelet protein spots in 2D gels in benign ovarian lesions (16 cases) and ovarian cancer, FIGO stages III-IV (20 cases). The predictive ability of the model was tested using 8 cases of the ovarian cancer, FIGO stages I-II, 9 cases of benign adnexal lesions and 10 cases of the ovarian cancer, FIGO stages III-IV. Protein spots selected by PLS-DA were ranked as variables of importance in the projection (VIP) by the strength of their input into the model. An analysis of the influence of co-morbidities and the intake of coagulation and platelet aggregation blockers was performed.

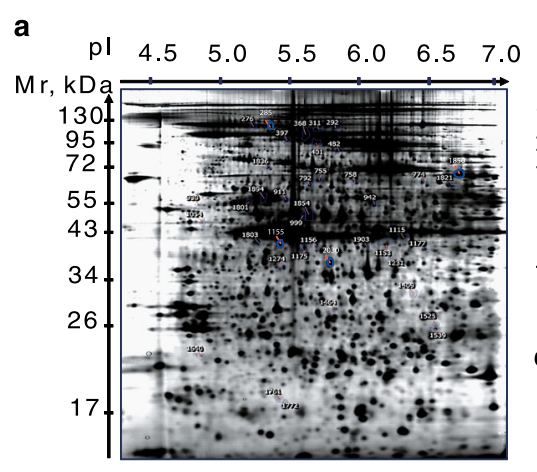

b $\quad$ oBenign adnexal lesions
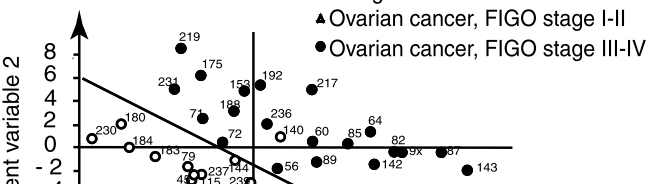

$\stackrel{\Phi}{\Xi}-6$
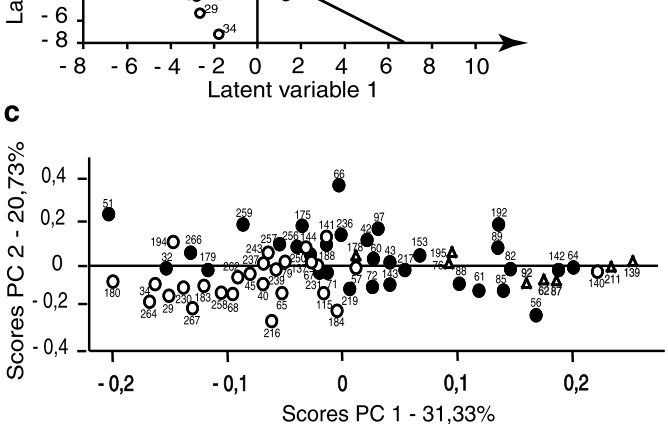

Fig. 1 Proteomics-based analysis of platelet proteins was based on the separation of proteins according to mass (Mr, kDa) and charge (pl) by $2 \mathrm{D}$ gel electrophoresis with further analysis of the expression of protein spots for marker identification. a 2D gel electrophoresis diagram of platelet proteins. Circles and numbers indicate the identified biomarkers. $\mathbf{b}$ The PLS-DA-based cross-validated model based on the partial least squares discriminate analysis of 2D gels for benign adnexal lesions (white circle) and ovarian cancer, FIGO stage III-IV (black circle) in accordance to the expression of all protein spots in the gel. c Principal component analysis (PCA) showing separation of the generated 2D gels for benign adnexal lesions (white circle), ovarian cancer, FIGO stage I-II (triangle) and FIGO stage III-IV (black circle) in accordance to the expression of selected biomarkers; percentage of variance $X$ explained by the two PCA components shown 
Western blot analysis for antibody identification and confirmation of protein identification was performed using 20 cases of benign adnexal lesions, 20 cases of ovarian cancer, FIGO stages III-IV and 8 cases of stages I-II (Table 1). The same cases were used for 2D electrophoresis (Additional file 1: Table S1). For protein panel verification, all analysed samples were randomized and distributed to four sets of gel separation batches. Each batch produced four equal gels, each of which, after transferring, was incubated with four different mixtures of primary antibodies against 16 proteins (Additional file 1: Table S2) for a total of 16 gels per data set. This experiment was repeated three times (sets 1-3). Protein expression levels were subjected to OPLS-DA, logistic regression and receiver-operator curve (ROC) analysis (MedCalc Software, Ostend, Belgium).

Verification using DigiWest analysis [19] was performed on an independent set of prospectively collected randomized platelet samples from patients with ovarian cancer, FIGO stages III-IV $(n=30)$, and benign adnexal control lesions $(n=29)$ (Table 1, Additional file 1: Table S1). Statistical analysis was OPLS-DA based.

\section{Results}

Cancer-related expression of platelet proteins in 2D gels Each 2D gel contained approximately 2000 protein spots (Fig. 1a). Initial PCA (Fig. 1c) of expression levels of significantly differentially expressed protein spots in $2 \mathrm{D}$ gels indicated a degree of separation between the three analysed patient groups: benign adnexal lesions, ovarian cancer, FIGO stages I-II and FIGO stages III-IV. PCA scores showing these groups are presented in Fig. 1c.

The PLS-DA cross-validated model based on the expression of all protein spots in 2D gels of benign adnexal lesions and ovarian cancer (FIGO stages III-IV) presented $96 \%$ sensitivity and $88 \%$ specificity for discrimination between these groups (Table 2a, Fig. 1b). The predictive ability of the built PLS-DA model was tested. We observed that all 8 cases ovarian cancer, FIGO stages I-II were recognised as cancer (1.00 sensitivity), and also 8 of 10 cases of ovarian cancer, FIGO stages III-IV (80\%). Four out of 9 cases of benign adnexal lesions were recognised as benign ( 0.44 specificity) (Table 2a). Forty-three protein variables with VIP $>2$ were selected for protein identification.

Table 2 Statistics for PLS-DA, OPLS-DA model, details for predictive and orthogonal parts; ROC analysis

A) PLS-DA-based analysis of protein spots expression in 2D

$\begin{array}{llllll}\text { Component } & \begin{array}{l}\text { Latent } \\ \text { variables }\end{array} & \text { R2X (cum) } & \text { Q2 (cum) } & \begin{array}{l}\text { CV-ANOVA, } \\ \text { p-value }\end{array} & \begin{array}{l}\text { permutation test, } \\ \text { p-value }\end{array} \\ \text { Model } & 3 & 0.318 & 0.72 & 8,5 * 10-9 & <0.001\end{array}$

B) OPLS-DA-based analysis of protein expression in western blot.

\begin{tabular}{|c|c|c|c|c|c|c|c|c|c|}
\hline Component & $\begin{array}{l}\text { Latent } \\
\text { variables }\end{array}$ & R2X (cum) & R2 (cum) & Q2 (cum) & $\begin{array}{l}\text { CV-ANOVA, } \\
\text { p-value }\end{array}$ & $\begin{array}{l}\text { permutation test, } \\
p \text {-value }\end{array}$ & & Sensitivity & Specificity \\
\hline Model & $1+1$ & 0.203 & 0.632 & 0.477 & 4.41E-14 & $<0.001$ & $\begin{array}{l}\text { calibration } \\
\text { set }\end{array}$ & 0.83 & 0.89 \\
\hline Predictive & 1 & 0.0717 & 0.632 & 0.477 & & & $\begin{array}{l}\text { validation } \\
\text { set }\end{array}$ & 0.88 & not tested \\
\hline Orthogonal & 1 & 0.131 & 0 & & & & & & \\
\hline \multicolumn{10}{|c|}{ ROC analysis of protein expression in western blot. } \\
\hline $\begin{array}{l}\text { Compared } \\
\text { groups }\end{array}$ & AUC & $\begin{array}{l}\text { standart } \\
\text { deviation }\end{array}$ & $\begin{array}{l}95 \% \text { confidence } \\
\text { interval }\end{array}$ & z statistics & p-value & & & Sensitivity & Specificity \\
\hline ROC 1 & 0.777 & 0.0418 & 0,695 to 0,859 & 6.639 & $<0,0001$ & & $\mathrm{ROC} 1$ & 60 & 83.33 \\
\hline ROC 2 & 0.831 & 0.0501 & 0,733 to 0,930 & 6.615 & $<0,0001$ & & $\mathrm{ROC2}$ & 83.33 & 76.19 \\
\hline \multicolumn{10}{|c|}{ ) OPLS-DA-based analysis of protein expression in Digi west. } \\
\hline Component & $\begin{array}{l}\text { Latent } \\
\text { variables }\end{array}$ & $\mathrm{R} 2 \mathrm{X}$ (cum) & R2 (cum) & Q2 (cum) & $\begin{array}{l}\text { CV-ANOVA, } \\
\text { p-value }\end{array}$ & $\begin{array}{l}\text { permutation test, } \\
\text { p-value }\end{array}$ & & Sensitivity & Specificity \\
\hline Model & $1+2$ & 0.24 & 0.785 & 0.345 & 4.50E-03 & $<0.001$ & test set & 0.7 & 0.83 \\
\hline Predictive & 1 & 0.037 & 0.785 & 0.345 & & & & & \\
\hline Orthogonal & 2 & 0.203 & & & & & & & \\
\hline
\end{tabular}

$R 2 X$ cumulative percentage of $X$ variance explained, $R 2$ cumulative percentage of $Y$ variance explained, $Q 2$ cumulative percentage of variance of $Y$ predicted, CV-ANOVA $p$-value $\mathrm{p}$-value of cross-validation ANOVA, permutaion test $p$-value $p$-value of (1000 iterations) permutation test 
Table 3 Protein identification

\begin{tabular}{|c|c|c|c|c|c|c|c|c|c|c|c|c|}
\hline \multirow{2}{*}{$\begin{array}{l}\text { Protein } \\
\text { spot } \\
\text { number } \\
\text { on 2D } \\
\end{array}$} & \multirow{2}{*}{$\begin{array}{l}\text { Gene } \\
\text { ontology } \\
\text { name }\end{array}$} & \multirow{2}{*}{ Protein name } & \multicolumn{2}{|c|}{ theoretical } & \multicolumn{2}{|c|}{ experimental } & \multirow{2}{*}{$\begin{array}{l}\text { NCBI accession } \\
\text { number }\end{array}$} & \multirow{2}{*}{$\begin{array}{l}\text { Sequence } \\
\text { coverage, } \\
\%\end{array}$} & \multirow{2}{*}{$\begin{array}{l}\text { Matched } \\
\text { peptides }\end{array}$} & \multirow{2}{*}{$\begin{array}{l}\text { Total } \\
\text { peptide } \\
\text { count }\end{array}$} & \multirow[t]{2}{*}{ score } & \multirow[t]{2}{*}{ msms } \\
\hline & & & $\mathrm{pl}$ & $\mathrm{Mr}, \mathrm{kDa}$ & $\mathrm{pl}$ & $\mathrm{Mr}, \mathrm{kDa}$ & & & & & & \\
\hline 1 & 2 & 3 & 4 & 5 & 6 & 7 & 8 & 9 & 10 & 11 & 12 & 13 \\
\hline 285 & ACTN1 & Alpha-actinin-1 isoform b & 5.2 & 104 & 5.5 & 100 & NP_001093 & 25 & 19 & 75 & 98 & - \\
\hline 1836 & ACTN4 & Alpha actinin 4, partial & 5.2 & 74 & 5.3 & 72 & AAH15620 & 14 & 9 & 30 & 68 & - \\
\hline 1153 & ACTB & beta actin variant, partial & 5.4 & 42 & 6.2 & 40 & BAD96752.1 & 31 & 9 & 48 & 71 & - \\
\hline 1803 & ACTB & actin beta & 5.2 & 39 & 5.3 & 42 & BAG62914.1 & 30 & 10 & 54 & 81 & - \\
\hline 1772 & AP4A & Bis(5'-nucleosyl)- tetraphosphatase & 5.1 & 17 & 5.4 & 17 & NP_001152 & 27 & 5 & 36 & 52 & 1 \\
\hline 1274 & CAPZA1 & $\begin{array}{l}\text { capping actin protein of muscle } \\
\text { Z-line alpha subunit } 1\end{array}$ & 6 & 32 & 5.4 & 40 & XP_005542394.1 & 54 & 11 & 60 & 106 & - \\
\hline 911 & CD41 & Integrin alpha-Ilb precursor variant & 5.7 & 60 & 5.4 & 60 & BAD92789.1 & - & - & - & 46 & 1 \\
\hline 276 & CD41 & $\begin{array}{l}\text { Integrin, alpha 2b (platelet } \\
\text { glycoprotein IIb of IIb/IIla complex, } \\
\text { antigen CD41), isoform CRA_a }\end{array}$ & 5.4 & 104 & 5.3 & 110 & EAW51594.1 & 24 & 17 & 49 & 122 & - \\
\hline 1761 & CD42A & glycoprotein IX platelet & 5.4 & 18 & 5.4 & 20 & AAH30229 & 27 & 5 & 43 & 53 & 2 \\
\hline 792 & CD61 & Platelet glycoprotein IIla, partial & 5 & 87 & 5.6 & 70 & AAA52600 & - & - & - & 15 & 1 \\
\hline 942 & CNDP2 & Cytosolic non-specific dipeptidase & 5.6 & 53 & 6 & 55 & BAG53426 & 22 & 8 & 48 & 51 & 3 \\
\hline 1539 & CRKL & Crk-lke protein & 6.3 & 34 & 6.5 & 26 & NP_005198 & 29 & 9 & 56 & 64 & 1 \\
\hline 1525 & ERP29 & $\begin{array}{l}\text { Erp28, endoplasmic reticulum } \\
\text { resident protein } 29 \text { isoform } 1 \\
\text { precursor }\end{array}$ & 6.8 & 29 & 6.5 & 27 & NP_006808 & 28 & 6 & 68 & 44 & 2 \\
\hline 1854 & FBG & Fibrinogen gamma chain & 5.5 & 48 & 5.6 & 50 & EAX04921 & 40 & 13 & 53 & 113 & - \\
\hline 397 & GELS & $\begin{array}{l}\text { Gelsolin isoform a precursor } \\
\text { (782 aa) }\end{array}$ & 5.9 & 86 & 5.4 & 95 & NP_000168 & - & - & - & 61 & 1 \\
\hline 401 & GELS & Gelsolin isoform b (731 aa) & 5.6 & 81 & 5.7 & 90 & NP_937895 & 12 & 9 & 50 & 45 & 2 \\
\hline 311 & HSPA9 & $\begin{array}{l}\text { Stress-70 potein, mitochondrial } \\
\text { precursor }\end{array}$ & 5.8 & 74 & 5.7 & 120 & NP_001126860 & 27 & 17 & 66 & 100 & 3 \\
\hline 1155 & $\mathrm{HP}$ & Haptoglobin & 6.3 & 38 & 5.4 & 42 & AAI07588.1 & 25 & 10 & 61 & 71 & - \\
\hline 482 & HSPA8 & Heat shock $70 \mathrm{kDa}$ protein $1 \mathrm{~A} / 1 \mathrm{~B}$ & 5.4 & 70 & 5.7 & 80 & P08107 & 13 & 6 & 56 & 29 & - \\
\hline 1115 & ILEU & Leukocyte elastase inhibitor & 5.9 & 43 & 6.3 & 43 & NP_109591 & 21 & 7 & 43 & 72 & - \\
\hline 1177 & MPST & $\begin{array}{l}\text { 3-mercaptopyruvate } \\
\text { sulfurtransferase }\end{array}$ & 6.8 & 35 & 6.4 & 37 & BAD92061.1 & 33 & 8 & 39 & 75 & - \\
\hline 1231 & NSFL1C & NSFL1 cofactor p47 isoform X8 & 5 & 31 & 6.2 & 38 & XP_011527607.1 & 25 & 5 & 46 & 38 & 1 \\
\hline 1850 & PGM1 & phosphoglucomutase-1 isoform 1 & 6.3 & 62 & 6.8 & 70 & NP_002624.2 & 11 & 5 & 32 & 33 & - \\
\hline 1464 & $\mathrm{PHB}$ & Prohibitin & 5.5 & 28 & 5.7 & 30 & XP_003912755.3 & 49 & 12 & 46 & 136 & - \\
\hline 1054 & $\mathrm{RNH1}$ & ribonuclease/angiogenin inhibitor 1 & 4.8 & 50 & 4.8 & 50 & AAH11186.1 & 11 & 5 & 25 & 45 & - \\
\hline 999 & PRKAR1A & $\begin{array}{l}\text { protein kinase CAMP-dependent } \\
\text { type I regulatory subunit alpha }\end{array}$ & 5.2 & 43 & 5.5 & 53 & XP_004041145.1 & 35 & 13 & 72 & 102 & \\
\hline 939 & PRKAR2B & $\begin{array}{l}\text { protein kinase CAMP-dependent } \\
\text { type II regulatory subunit beta }\end{array}$ & 5 & 45 & 4.8 & 55 & BAG54705.1 & 19 & 6 & 27 & 41 & 2 \\
\hline 1175 & SRB6 & Serpin B6 & 4.2 & 39 & 5.6 & 40 & XP_011512978.1 & 34 & 10 & 45 & 76 & - \\
\hline 1821 & SRC & $\begin{array}{l}\text { Protooncogene tyrosine-protein } \\
\text { kinase Src }\end{array}$ & 7.1 & 60 & 6.6 & 60 & NP_005408.1 & 13 & 8 & 54 & 39 & - \\
\hline 1801 & TUBA4A & Tubulin alpha-4A chain & 4.9 & 49 & 5.1 & 55 & NP_001265481.1 & 23 & 10 & 56 & 73 & - \\
\hline 1801 & TUBA1C & tubulin alpha 1c & 4.9 & 59 & 5.1 & 55 & BAH11541.1 & 23 & 10 & 56 & 68 & \\
\hline 758 & TLN1 & Talin 1 & 5.8 & 272 & 5.9 & 70 & AAF27330 & 7 & 13 & 43 & 42 & 1 \\
\hline 755 & TLN1 & Talin 1 & 5.8 & 272 & 5.8 & 70 & AAF27330 & 9 & 15 & 46 & 54 & - \\
\hline 292 & TLN1 & Talin 1 & 5.8 & 272 & 5.8 & 110 & AAF27330 & 14 & 33 & 84 & 106 & - \\
\hline
\end{tabular}


Table 3 Protein identification (Continued)

\begin{tabular}{|c|c|c|c|c|c|c|c|c|c|c|c|c|}
\hline \multirow{2}{*}{$\begin{array}{l}\text { Protein } \\
\text { spot } \\
\text { number } \\
\text { on 2D } \\
\end{array}$} & \multirow{2}{*}{$\begin{array}{l}\text { Gene } \\
\text { ontology } \\
\text { name }\end{array}$} & \multirow{2}{*}{ Protein name } & \multicolumn{2}{|c|}{ theoretical } & \multicolumn{2}{|c|}{ experimental } & \multirow{2}{*}{$\begin{array}{l}\text { NCBI accession } \\
\text { number }\end{array}$} & \multirow{2}{*}{$\begin{array}{l}\text { Sequence } \\
\text { coverage, } \\
\%\end{array}$} & \multirow{2}{*}{$\begin{array}{l}\text { Matched } \\
\text { peptides }\end{array}$} & \multirow{2}{*}{$\begin{array}{l}\text { Total } \\
\text { peptide } \\
\text { count }\end{array}$} & \multirow[t]{2}{*}{ score } & \multirow[t]{2}{*}{ msms } \\
\hline & & & $\mathrm{pl}$ & $\mathrm{Mr}, \mathrm{kDa}$ & $\mathrm{pl}$ & $\mathrm{Mr}, \mathrm{kDa}$ & & & & & & \\
\hline 1 & 2 & 3 & 4 & 5 & 6 & 7 & 8 & 9 & 10 & 11 & 12 & 13 \\
\hline 774 & TLN1 & Talin 1 & 5.8 & 272 & 6.4 & 70 & AAF27330 & - & - & - & 25 & 1 \\
\hline 1409 & TLN1 & Talin 1 & 5.8 & 272 & 6.4 & 34 & AAF23322.1 & 6 & 15 & 39 & 47 & - \\
\hline 1640 & TPM1 & Tropomyosin 1, alpha & 5 & 20 & 4.7 & 20 & XP_005254707 & 23 & 6 & 64 & 30 & - \\
\hline 1894 & TUBA6 & Tubulin alpha-6 chain, partial & 5 & 47 & 5.3 & 56 & EHH66249.1 & 34 & 10 & 56 & 80 & - \\
\hline 1894 & TUBA8 & tubulin alpha-8 & 5 & 43 & 5.3 & 56 & XP_007469555.1 & 33 & 10 & 56 & 82 & \\
\hline 1894 & TUBA1C & tubulin alpha-1C chain & 5 & 47 & 5.3 & 56 & XP_004646666.1 & 35 & 10 & 56 & 81 & \\
\hline 999 & TUBB1 & tubulin beta-1 chain isoform X7 & 5.1 & 43 & 5.5 & 53 & XP_018872841.1 & 42 & 12 & 72 & 93 & - \\
\hline 1850 & WDR1 & $\begin{array}{l}\text { WD repeat-containing protein } 1 \\
\text { iso } 1\end{array}$ & 6.4 & 59 & 6.8 & 70 & AAD05045 & 35 & 18 & 60 & 135 & - \\
\hline
\end{tabular}

1 - number of a protein spot on 2-D gel,

2 - gene ontology name,

3 - protein name,

4 - isoelectric point of a protein spots according to the position on 2D gel,

5 - protein mass of a protein according to the position of a spot on $2 \mathrm{D}$ gel,

6 - isoelectric point of a protein spot as provided by Mascot search database,

7 - protein mass as provided by Mascot search database,

8 - protein accession number according to $\mathrm{NCBI}$,

9 - matching of the experimental peptide sequence to a peptide sequence provided by NCBI,

10 - number of identified peptides that matched to the peptides of a peptide sequence provided by $\mathrm{NCBI}$

11 - total amount of peptides in a peptide sequence provided by NCBI,

12 - score provided by Mascot search engine,

13 - performed msms for the certainty of protein identification.

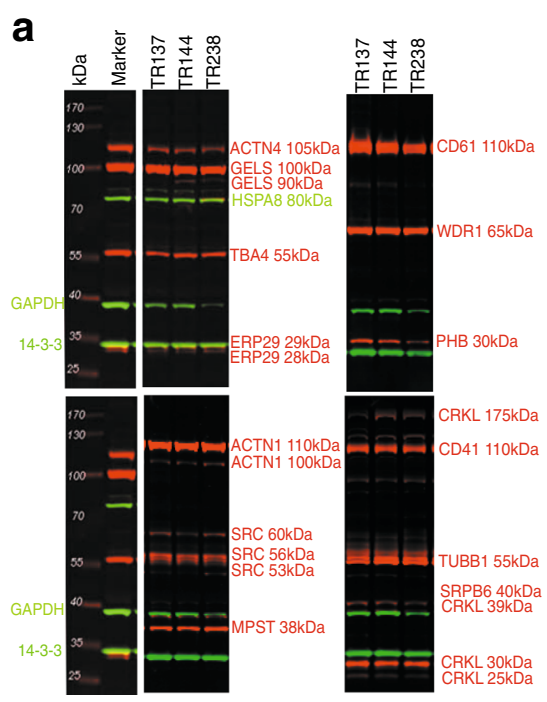

b
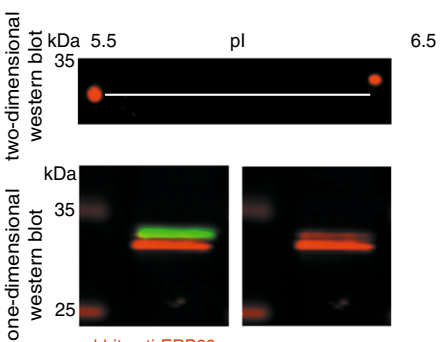

rabbit anti-ERP29

mouse anti-ERP29

6.5$$
\text { . }
$$

Fig. 2 Western blot analysis. a Confirmation of protein identification by western blot using antibodies against 15 selected proteins, and normalisation against14-3-3-gamma (loading control). b Western blot detection of ERP29. This example compares Mr/pl from 2D gel and Western blot where the mouse anti-ERP29 detects protein spot \#1525, while the rabbit anti-ERP29 detects an additional protein spot, possibly an isoform of ERP29 
Co-morbidities and use of of coagulation and platelet aggregation blockers did not influence the predictive ability of the model. The PLS-DA model suggested a list of protein spots for protein identification as potential biomarkers, which could be evaluated from the VIP plot.

\section{Identification of platelet protein biomarkers and confirmation of identification}

A total of 35 proteins were identified in 37 protein spots excised from 2D gels (Table 3).

A number of proteins were excluded due to low quality and/or low expression level that made identification by mass spectrometry unfeasible. Visual representation of the location of the identified spots may be found in Fig. 1a.

Confirmation of the protein identification was performed by western blot analysis of the samples used for 2D electrophoresis. Antibodies against 16 proteins were analysed. Protein identities with the highest VIP $<20$ were prioritised for analysis. Antibodies were selected based on the qualitative and quantitative recognition of protein bands, and protein detection was confirmed using positive control cell lines (Additional file 1: Table S2). Initially, we analysed several antibodies against each protein and identified useful antibodies for detection of biomarkers from the 2D gels (Fig. 2).

Several isoforms of the identified proteins were detected by western blot. ERP29 was detected in both 2D and western blot at around $29 \mathrm{kDa}$ as a double band, however only the upper band corresponded to protein spot \#1525 from the 2D analysis. The identified isoform, with NCBI accession number NP-006808, had both experimental and theoretical pI of around 6.5. The particular band could be singled out by a mouse monoclonal antibody (83,073, Abcam, Cambridge, UK) and was confirmed by 2D Western blot (Fig. 2b). CRKL was located at $25 \mathrm{kDa}$ on $2 \mathrm{D}$ and in western blot the correct isoform was identified among four detected bands. Finally, both the $60 \mathrm{kDa}$ and $53 \mathrm{kDa}$ isoforms of SRC were recognised as part of the biomarker panel.

\section{Verification of platelet biomarkers by western blot and DigiWest data}

Expression of proteins in western blot was normalized against the levels of 14-3-3-gamma, which is a more stable and relevant loading control for platelet proteins compared to GAPDH [18]. PCA was performed individually in each set of blotted membranes in order to look for major trends and grouping of the samples by observing the scores plots. These represented three repetitions of the experiment, with four groups per experiment. The PCA scores plots showed consistent separation between benign adnexal lesions from the cases of ovarian cancer, FIGO stages III-IV, as it was observed in 10 of the 12 PCA's scores plots.

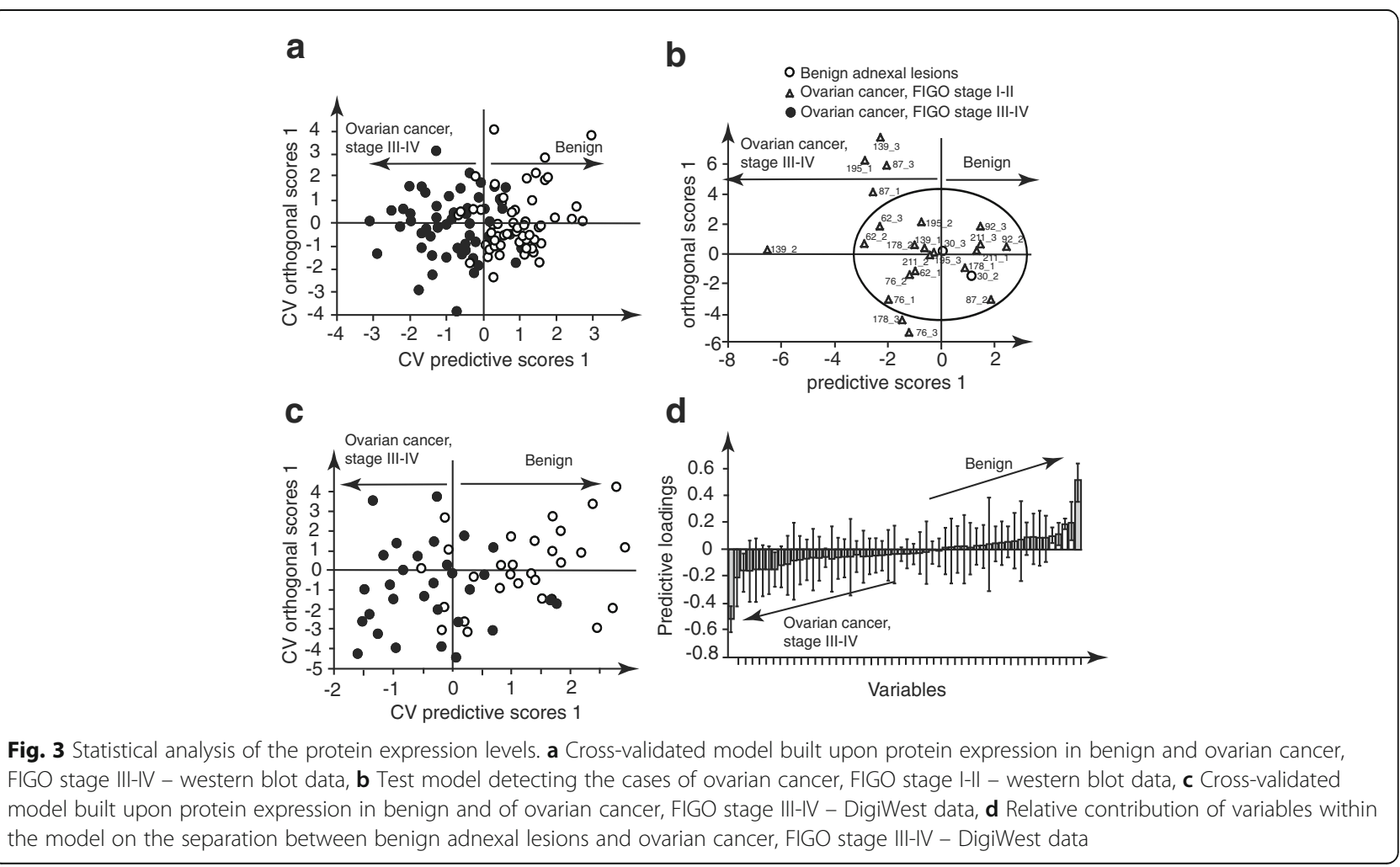


There was nonetheless some intrinsic batch variability, which could potentially be explained primarily by differences in the gels prepared for each batch, uneven protein transfer from gel to membrane, and suboptimal quantification of the protein bands expressed. Due to such variability, data were centred per batch previous to OPLS-DA modeling. After proper validation of the OPLS-DA model as described in the statistical section, results of the verification by western blot revealed a sensitivity of $83 \%(50 / 60)$ and a specificity of $89 \%$ (53/60) for separation between benign adnexal lesions and ovarian cancer, FIGO stages III-IV (Fig. 3a, Table 2b).

Next, model was tested for its predictive capacity. The correct prediction of two out of three samples per case was set as an acceptance criterion. Seven out of eight cases of ovarian cancer, FIGO stages I-II were predicted correctly ( $88 \%$ sensitivity). Sample 30 was reclassified by histology as benign and the prediction model confirmed this reclassification (Fig. 3b). Nine protein variables were suggested as a biomarker panel. In ovarian cancer, FIGO stages III-IV, seven protein variables were up-regulated and two variables were down-regulated. The ROC analysis of the detected nine-variable panel suggested discrimination between benign adnexal lesions and ovarian cancer, FIGO stages III-IV with a sensitivity of $60 \%$ and a specificity of $83 \%$ (Table 2c - ROC1) and between benign adnexal lesions and ovarian cancer, FIGO stages I-II with a sensitivity of $83 \%$ and a specificity of $76 \%$ (Table 2c - ROC2).
Next, the panel was verified by DigiWest with inclusion of a new, larger set of samples that were not previously used for 2D gel electrophoresis and western blot analysis. The expression profiles were analysed by OPLS-DA and the DigiWest based prediction model suggested a sensitivity of $70 \%(21 / 30)$ and a specificity of 83\% (24/29) for the separation between benign adnexal lesions and ovarian cancer, FIGO stages III-IV (Fig. 3c, Table $2 \mathrm{~d}$ ). The verification of biomarker candidates by DigiWest suggested seven protein variables as seen in the loadings plot in Fig. 3d; three protein variables were increased in ovarian cancer, FIGO stages III-IV and four were decreased. We observed a correspondence between western blot and DigiWest analysis regarding the potential value of six identified proteins as biomarkers, of which three were increased in ovarian cancer, FIGO stages III-IV and three were decreased in both western blot and DigiWest.

\section{Discussion}

In this study, we analysed the proteome of platelets isolated from peripheral blood of patients with ovarian cancer, FIGO stages I-II and III-IV, and benign adnexal lesions. By PLS-DA modelling of protein expression in 2D gels we observed the possibility to correctly differentiate between cases of benign adnexal lesions and ovarian cancer, FIGO stages III-IV, and correctly predict cases of FIGO stages I-II. These findings were verified by western blot and DigiWest.

Table 4 Function of proteins biomarkers in relation to ovarian cancer and platelets

\begin{tabular}{|c|c|c|}
\hline \multirow[t]{2}{*}{ Protein name } & \multicolumn{2}{|l|}{ Associated pathologic conditions } \\
\hline & ovarian cancer & platelet disorders \\
\hline ACTN1 & not studied & macrotrombocytopenia $[37,38]$ \\
\hline ACTN4 & $\uparrow$ in ovarian cancer [39] & myelodysplastic syndrome $[38,40]$ \\
\hline CD41/CD61 & platelets contribute to ovarian cancer growth [35] & deficient in Glanzmann thrombasthenia type II [41] \\
\hline CRKL & $\uparrow$ in ovarian cancer [42] & ST - elevated myocadial infarction [43] \\
\hline ERP29 & not studied & mediator of thrombus formation [44] \\
\hline GELS & $\uparrow$ in serum in ovarian cancer [45] & $\begin{array}{l}\uparrow \text { in megakaryoblastic leukemia [46], } \uparrow \text { in thrombin-activated } \\
\text { platelets [47] }\end{array}$ \\
\hline HSPA8 & $\uparrow$ in ovarian cancer, a potential therapy target [48] & mediator of thromboembolism [49] \\
\hline MPST & not studied & not clarified \\
\hline $\mathrm{PHB}$ & $\begin{array}{l}\uparrow \text { in paclitaxel-resistant ovarian cancer [30] } \downarrow \text { in platinum-resistant } \\
\text { ovarian cancer [32] }\end{array}$ & mediator of platelet aggregation [50] \\
\hline SRC & $\begin{array}{l}\text { therapy-target for thyrosine-kinase inhibitor in ovarian cancer [51], } \\
\text { resistance to cis-platin [33] }\end{array}$ & ST - elevated myocadial infarction [43] \\
\hline SERPINB6 & not studied & inhibitor of thrombin [25] \\
\hline TLN1 & $\uparrow$ in ovarian cancer [52], resistance to cis-platin [33] & myelodysplastic syndrome [40] \\
\hline TUBB1, TUBA4 & $\uparrow$ in ovarian cancer, mediator of paclitaxel resistance [31] & $\begin{array}{l}\uparrow \text { in thrombin-activated platelets [47], gene mutation in } \\
\text { autosomal dominant macrothrombocytopenia [25] }\end{array}$ \\
\hline WDR1 & $\uparrow$ in ovarian cancer [53], resistance to cis-platin [34] & mediator of TLN1-induced activation of CD41/CD61 [54] \\
\hline
\end{tabular}

$\uparrow$ corresponds up-regulation, $\downarrow$ corresponds down-regulation 
In the prospectively collected clinical material, there were 57 cases of benign adnexal lesions, 49 cases of ovarian cancer, FIGO stages III-IV, and 8 cases of ovarian cancer, FIGO stages I-II. Overrepresentation of advanced ovarian cancer patients (80\% of all cases) in our study reflects the worldwide situation regarding the detection rate of the disease at its advanced stages [1]. The initial PCA provided an indication of degree of correspondence between protein profiles of the compared groups. PLS-DA allowed us to build a multivariate regression model. Through PLS-DA it became possible to 1) "filter" the high level of biological background noise by using only the latent variables related to the biological variation of interest, 2) build a training model and use it to predict the class of earlier cancer test samples, and 3) identify the most discriminant variables within the multiplex profile by observing their variable importance in projection (VIP), i.e. ranking in the model [22-24].

Our proteome analysis was based on 2D gel electrophoresis, which made it possible to identify full-length proteins and also their isoforms with regards to their relevance for the protein marker panel. The verification of identified platelet proteins suggested the possibility for separating benign adnexal lesions, ovarian cancer, FIGO stages I-II and III-IV. However, verification by western blot has inherently several disadvantages, such as gel batch variability, protein transfer limitations, and semi-quantitive output. DigiWest, a recently developed system that represents a highthroughput multiplex version of the classical western blot method, uses a bead-based microarray platform for signal generation [19]. The sensitivity, signal linearity, and reproducibility of DigiWest are comparable to or exceed the best available western blot systems. Compared to the western blot method, DigiWest provides higher reproducibility with simultaneous analysis of up to 100 samples and quantification of individual cases.

The function of the 16 identified and immunovalidated platelet proteins was described using the Platelet Web database [25] (Additional file 1: Table S3).

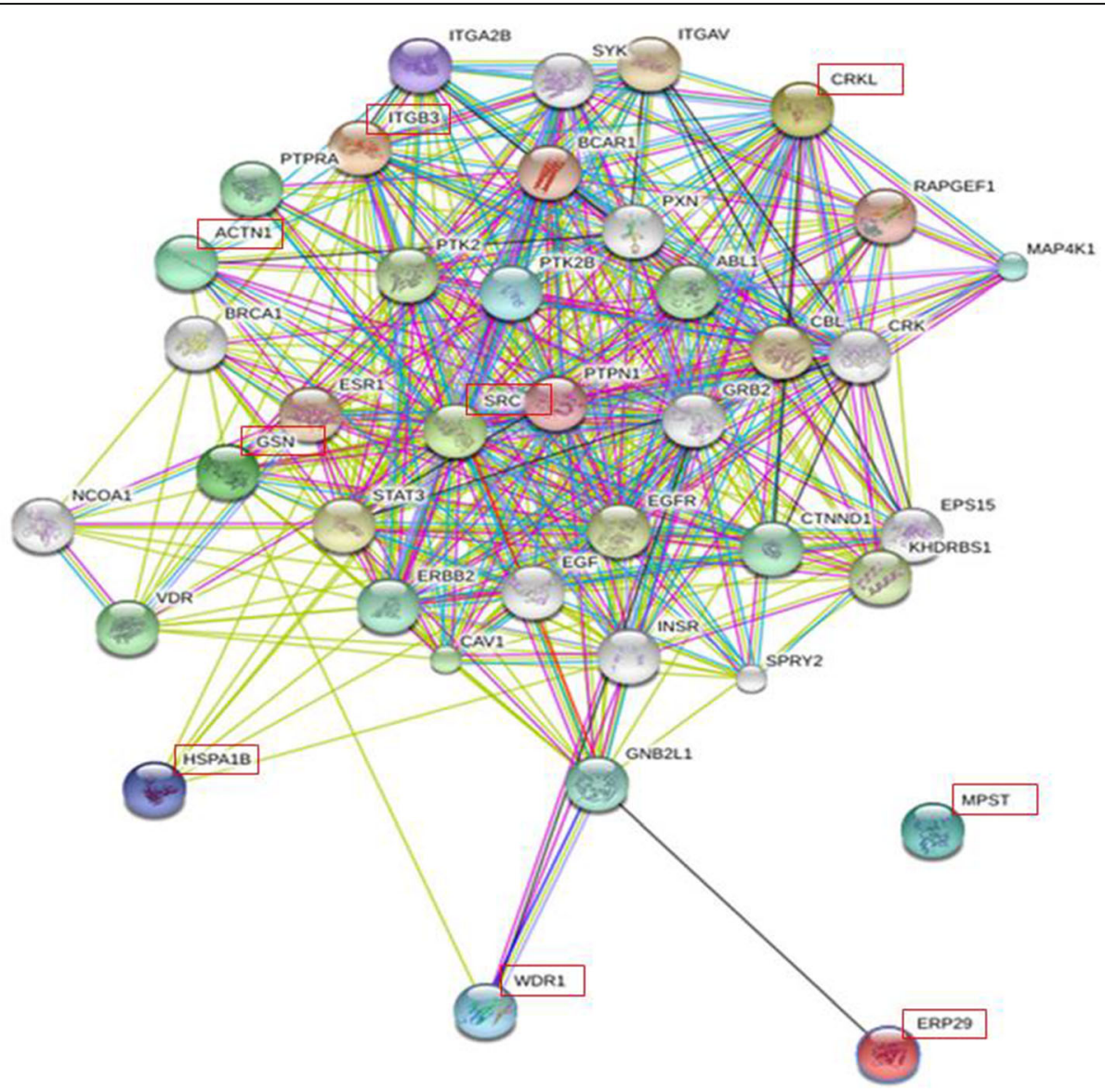

Fig. 4 Functional interaction profile of identified platelet proteins [36]. Lines represent interaction, where thick lines suggest a substantial number of references, thin lines correspond to single studies, arrows point the direction of activation influence, and block signs describe inhibitory actions 
Most of these proteins are reported to have a functional relevance to ovarian cancer, normal platelet biology and platelet-associated pathological conditions (Table 4). Published proteomics and molecular biology studies suggest up-regulation of ACTN4, CRKL, GELS, HSPA8, talin-1, tubulins and WDR1 in ovarian cancer. Expression changes and possible functional impact of ACTN1 [26], MPST [27], ERP29 [28] and SERPINB6 [29] are reported for several cancers, but not for ovarian cancer. PHB, SRC, talin-1, tubulins and WDR1 are related to development of ovarian cancer resistance to paclitaxel $[30,31]$ and cis-platin [32-34]. An interesting observation is an increased expression level of CD41/CD61 in platelets associated with tumor xenografts as well as enhanced tumor growth in the presence of platelets [35].

Using the STRING database [36], we analyzed potential interactions and functional impact of the identified platelet proteins on other known protein targets (Additional file 1: Table S4, Fig. 4). Most described protein interactions are related to CRKL, SRC, CD61, GELS (GSN), and ACTN1, while information is limited regarding the interaction profile of MPST, ERP29, HSPA8, and WDR1.

Limitations of the current study include dependency of sensitivity and specificity on the quantitative properties of the verification method and analysis of relatively small groups of clinical material. Multivariate PLS-DA-based statistics partially allowed us to overcome the problem of small clinical groups, however, further validation using clinical material from patients with early-stage ovarian cancer and borderline ovarian tumors is expected to strengthen the diagnostic sensitivity and specificity. Combination of the marker panel with the TVS protocol, which evaluates malignant potential of adnexal masses, towards a biochemical-instrumental test is the final goal. The objective diagnosis of adnexal lesions will help clinicians to correctly refer patients to a gynaecological cancer specialist, thus minimizing the cost of additional examinations and delays for patients needing advanced treatment. The panel detected is currently being developed as a new non-invasive in vitro diagnostic multivariate index-based analytical method for differentiation of adnexal lesions.

\section{Conclusion}

The identified platelet protein panel allows for differentiation between benign adnexal lesions and ovarian cancers of FIGO stages III-IV. Correct prediction of seven out of eight cases of ovarian cancer, FIGO stages I-II was possible through multivariate prediction modeling based on platelet protein expression profiles.

\section{Additional file}

Additional file 1: Table S1. Detailed description of the clinical material. Table S2. Description of the primary antibodies. Table S3. Function of proteins biomarkers, relation to ovarian cancer and platelet function. Table S4. Predicted functional partners for identified biomarkers. (XLSX $32 \mathrm{~kb}$ )

\begin{abstract}
Abbreviations
2D: Two-dimensional; ANOVA: Analysis of variance; AUC: Area under the curve; CV: Cross validation; DA: Discriminant analysis; FIGO: International Federation of Gynaecology and Obstetrics; IOTA: International Ovarian Tumor Association.; LDS: Lithium dodecyl sulfate.; PCA: Principal components analysis.; PF-4: Platelet factor 4.; PLS: Projection to latent structures (or partial least squares).; PMF: Peptide mass fingerprint.; RCF: Relative centrifugal force.; ROC: Receiver-operator curve.; RMI: Risk of malignancy index.;

STED: Stimulated emission depletion.; TVS: Transvaginal ultrasound.; VEGF: Vascular endothelial growth factor.; VIP: Variable importance in projection.; $X$ : Data matrix (number of rows equal to number of samples, number of columns equal to number of variables).; Y: Column vector (with one element per sample).
\end{abstract}

\section{Acknowledgements}

We acknowledge Teddy Primack and Michael Vanlandewijck for language assistance.

\section{Funding}

This work was supported by grants from the Cancer Research Foundations of Radiumhemmet, Stockholm Count County: HMT 20130704 and HMT 20140754, KI Fonder 2013fobi37433, Dagmar Ferbs Minnesfond 2012-2016, Vinnova 2014-03458 to NeoProteomics AB.

\section{Availability of data and materials}

All data generated or analysed during this study are included in this published article and its Additional files.

\section{Authors' contributions}

$L M, F B, A G, W J$, EE planned the project, selected patients, interpreted results, $\mathrm{LM}$ and $\mathrm{EE}$ recruited patients for the study, BS, BC, GS performed preparation of the platelet fraction, 2D gel electrophoresis, western blot, EU performed mass-spectrometry, TM performed Digi west analysis, XL, BJ performed analysis of platelets using high-resolution microscopy, PR performed statistical analysis, LM performed ROC curve analysis, LM, FB, PR and AG were the major contributors in writing the manuscript. All authors read and approved the final manuscript.

\section{Ethics approval and consent to participate}

Approval for the study was given by the local ethical committee of Stockholm County Council, Dnr 2010/504-31. Written consent for participation and data presentation was received from the patients who volunteered to take part in the study.

\section{Consent for publication}

Not applicable.

\section{Competing interests}

Authors Gustafsson Sonja, Björklund Christina, Franzén Bo and Auer Gert are affiliated to NeoProteomics AB. Other authors declare no competing interests.

\section{Publisher's Note}

Springer Nature remains neutral with regard to jurisdictional claims in published maps and institutional affiliations.

\section{Author details}

'Department of Obstetrics and Gynaecology, Academical Uppsala University Hospital, Uppsala University, SE-751 85 Uppsala, Sweden. ${ }^{2}$ Institute of Women's and Children's Health, Karolinska Institute, SE-171 76 Stockholm, Sweden. ${ }^{3}$ Department of Oncology and Pathology, Cancer Centre Karolinska, 
Karolinska Institute, SE-171 76 Stockholm, Sweden. ${ }^{4}$ Department of Epidemiology and Biostatistics, MRC-PHE Centre for Environment and Health, School of Public Health, Imperial College London, St. Mary's Campus, Norfolk Place, W2 1PG, London, England, UK. ${ }^{5}$ Ludwig Institute for Cancer Research Ltd, Box 595, SE-751 24 Uppsala, Sweden. ${ }^{6}$ NeoProteomics AB, Cancer Centre Karolinska, SE-17176 Stockholm, Sweden. ${ }^{7}$ NMI Natural and Medical Sciences Institute at the University of Tübingen, 72770 Reutlingen, Germany. ${ }^{8}$ Experimental Biomolecular Physics, Department of Applied Physics, Royal Institute of Technology, AlbaNova University Center, SE-106 91 Stockholm, Sweden. ${ }^{9}$ Department of Obstetrics and Gynaecology, Department of Clinical Science and Education, Södersjukhuset, SE-118 83 Stockholm, Sweden.

Received: 5 September 2017 Accepted: 3 January 2018 Published online: 12 January 2018

\section{References}

1. De Angelis R, Sant M, Coleman MP, Francisci S, Baili P, Pierannunzio D, et al. Cancer survival in Europe 1999-2007 by country and age: results of EUROCARE-5-a population-based study. Lancet Oncol. 2014;15(1):23-34.

2. Jacobs IA, Menon U, Ryan A, Gentry-Maharaj A, Burnell M, Kalsi JK, et al. Ovarian cancer screening and mortality in the UK collaborative trial of ovarian cancer screening (UKCTOCS): a randomised controlled trial. Lancet. 2016;387(10022):945-56.

3. Biggs WS, Marks ST. Diagnosis and Management of Adnexal Masses. Am Fam Physician. 2016;93(8):676-81.

4. Valentin L, Ameye L, Savelli L, Fruscio R, Leone FP, Czekierdowski A, et al. Adnexal masses difficult to classify as benign or malignant using subjective assessment of gray-scale and Doppler ultrasound findings: logistic regression models do not help. Ultrasound in Obstet Gynecol. 2011;38(4):456-65.

5. Timmerman D, Valentin L, Bourne $T H$, Collins WP, Verrelst $H$, Vergote I. Terms, definitions and measurements to describe the sonographic features of adnexal tumors: a consensus opinion from the international ovarian tumor analysis (IOTA) group. Ultrasound in Obstet Gynecol. 2000;16(5):500-5.

6. Kaijser J, Van Belle V, Van Gorp T, Sayasneh A, Vergote I, Bourne T, Van Calster B, Timmerman D. Prognostic value of serum HE4 levels and risk of ovarian malignancy algorithm scores at the time of ovarian cancer diagnosis. Int J Gynecol Cancer. 2014;24(7):1173-80.

7. Allensworth SK, Langstraat CL, Martin JR, Lemens MA, McGree ME, Weaver $\mathrm{AL}$, et al. Evaluating the prognostic significance of preoperative thrombocytosis in epithelial ovarian cancer. Gynecol Oncol. 2013;130(3): 499-504.

8. Wan S, Lai Y, Myers RE, Li B, Hyslop T, London J, et al. Preoperative platelet count associates with survival and distant metastasis in surgically resected colorectal cancer patients. J Gastrointest Cancer. 2013:44(3):293-304.

9. Gay LJ, Felding-Habermann B. Contribution of platelets to tumor metastasis. Nat Rev Cancer. 2012;11:123-34.

10. Buergy D, Wenz F, Groden C, Brockmann MA. Tumor-platelet interaction in solid tumors. Int J Cancer. 2012:130:2747-60.

11. Senzel L, Gnatenko DV, Bahou WF. The platelet proteome. Curr Opin Hematol. 2009;16(5):329-33.

12. Klement GL, Yip TT, Cassiola F, Kikuchi L, Cervi D, Podust V, et al. Platelets actively sequester angiogenesis regulators. Blood. 2009;133:2835-42.

13. Folkman J, Klement G. Platelet biomarkers for the detection of disease. Patent US20060204951A1, 2006.

14. Rönnlund D, Yang Y, Blom H, Auer G, Widengren J. Fluorescence nanoscopy of platelets resolves platelet-specific storage, release and uptake of proteins, opening for future diagnostic applications. Adv. Healthcare Mater. 2012;1 (6):707-13.

15. Reicheltová Z, Májek P, Riedel T, Suttnar J, Dyr JE. Simplified platelet sample preparation for SDS-PAGE-based proteomic studies. Proteomics Clin Appl. 2012;6(7-8):374-81.

16. Bradford MM. Rapid and sensitive method for the quantitation of microgram quantities of protein utilizing the principle of protein-dye binding. Anal Biochem. 1976;72:248-54

17. Lomnytska M, Becker S, Gemoll T, Lundgren C, Habermann J, Olsson A, et al. Impact of genomic stability on protein expression in endometrioid endometrial cancer. Br J Cancer. 2012;106(7):1297-305.

18. Baumgartner R, Umlauf E, Veitinger M, Guterres S, Rappold E, Babeluk R, et al. Identification and validation of platelet low biological variation proteins, superior to GAPDH, actin and tubulin, as tools in clinical proteomics. J Proteome. 2013;94:540-51.
19. Treindl F, Ruprecht B, Beiter Y, Schultz S, Döttinger A, Staebler A, et al. A bead-based western for high-throughput cellular signal transduction analyses. Nat Commun. 2016;7:12852.

20. Jolliffe IT. Principal Component Analysis, Series:Springer Series in Statistics. 2nd ed. Springer: NY; 2002.

21. Wold S, Sjöström M, Eriksson L. PLS-regression: a basic tool of chemometrics. Chemom Intell Lab Syst. 2011;58:109-30.

22. Ottervald J, Franzén B, Nilsson K, Andersson LI, Khademi M, Eriksson B, et al. Multiple sclerosis: identification and clinical evaluation of novel CSF biomarkers. J Proteome. 2010;73(6):1117-32

23. Bylesjo M, Rantalainen M, Cloarec O, Nicholson JK, Holmes E, Trygg JOPLS Discriminant analysis: combining the strengths of PLS-DA and SIMCA classification. J Chemometrics. 2006;20(9-10):341-51.

24. Pinto R.C. Chemometrics methods and strategies in metabolomics. In: Sussulini a. (eds) metabolomics: from fundamentals to clinical applications. Advances in experimental medicine and biology, vol 965. Springer, Champions, 2017

25. Boyanova D, Nilla S, Birschmann I, Dandekar T, Dittrich M. PlateletWeb: a systems biologic analysis of signaling networks in human platelets. Blood. 2012;119(3):e22-34.

26. Kanamori $H$, Kawakami T, Effendi $K$, Yamazaki $K$, Mori $T$, Ebinuma $H$, et al. Identification by differential tissue proteome analysis of talin-1 as a novel molecular marker of progression of hepatocellular carcinoma. Oncology. 2011;80(5-6):406-15.

27. Bronowicka-Adamska P, Bentke A, Wróbel M. Hydrogen sulfide generation from l-cysteine in the human glioblastoma-astrocytoma U-87 MG and neuroblastoma SHSY5Y cell lines. Acta Biochim Pol. 2017;64(1):171-6.

28. Fan NJ, Gao JL, Liu Y, Song W, Zhang ZY, Gao CF. Label-free quantitative mass spectrometry reveals a panel of differentially expressed proteins in colorectal cancer. Biomed Res Int. 2015:365068.

29. Ha ES, Choi S, In KH, Lee SH, Lee EJ, Lee SY, et al. Identification of proteins expressed differently among surgically resected stage I lung adenocarcinomas. Clin Biochem. 2013;46(4-5):369-77.

30. Cao L, Li X, Zhang Y, Peng F, Yi H, Xu Y, et al. Proteomic analysis of human ovarian cancer paclitaxel-resistant cell lines. Zhong Nan Da Xue Xue Bao Yi Xue Ban. 2010;35(4):286-94.

31. Vergara D, Tinelli A, lannone A, Maffia M. The impact of proteomics in the understanding of the molecular basis of paclitaxel-resistance in ovarian tumors. Curr Cancer Drug Targets. 2012;12(8):987-97.

32. Dai Z, Yin J, He H, Li W, Hou C, Qian X, et al. Mitochondrial comparative proteomics of human ovarian cancer cells and their platinum-resistant sublines. Proteomics. 2010;10(21):3789-99.

33. Sansing HA, Sarkeshik A, Yates JR, Patel V, Gutkind JS, Yamada KM, Berrier $A L$. Integrin a $\beta 1, a v \beta, a 6 \beta$ effectors p130Cas, Src and talin regulate carcinoma invasion and chemoresistance. Biochem Biophys Res Commun. 2011;406(2):171-6.

34. Kim SW, Kim S, Nam EJ, Jeong YW, Lee SH, Paek JH, et al. Comparative proteomic analysis of advanced serous epithelial ovarian carcinoma: possible predictors of chemoresistant disease. OMICS. 2011;15(5):281-92.

35. Yuan L, Liu X. Platelets are associated with xenograft tumor growth and the clinical malignancy of ovarian cancer through an angiogenesis-dependent mechanism. Mol Med Rep. 2015;11(4):2449-58.

36. Franceschini A, Szklarczyk D, Frankild S, Kuhn M, Simonovic M, Roth A, et al. STRING v9.1: protein-protein interaction networks, with increased coverage and integration. Nucleic Acids Res. 2013;41(Database issue):D808-15.

37. Westbury SK, Shoemark DK, Mumford AD. ACTN1 variants associated with thrombocytopenia. Platelets. 2017;28(6):625-7.

38. Finamore F, Pieroni L, Ronci M, Marzano V, Mortera SL, Romano M, et al. Proteomics investigation of human platelets by shotgun nUPLC-MSE and 2DE experimental strategies: a comparative study. Blood Transfus. 2010; 8(Suppl 3):s140-8

39. Honda K. The biological role of actinin-4 (ACTN4) in malignant phenotypes of cancer. Cell Biosci. 2015;5:41

40. Fröbel J, Cadeddu RP, Hartwig S, Bruns I, Wilk CM, Kündgen A, et al. Platelet proteome analysis reveals integrin-dependent aggregation defects in patients with myelodysplastic syndromes. Mol Cell Proteomics. 2013;12(5):1272-80.

41. Mutreja D, Sharma RK, Purohit A, Aggarwal M, Saxena R. Evaluation of platelet surface glycoproteins in patients with Glanzmann thrombasthenia: association with bleeding symptoms. Indian J Med Res. 2017;145(5):629-34.

42. Luo LY, Hahn WC. Oncogenic signaling adaptor proteins. J Genet Genomics. 2015;42(10):521-9. 
43. Parguiña AF, Grigorian-Shamagian L, Agra RM, López-Otero D, Rosa I, Alonso J, et al. Variations in platelet proteins associated with ST-elevation myocardial infarction: novel clues on pathways underlying platelet activation in acute coronary syndromes. Arterioscler Thromb Vasc Biol. 2011; 31(12):2957-64.

44. Schulman S, Bendapudi P, Sharda A, Chen V, Bellido-Martin L, Jasuja R, et al. Extracellular thiol isomerases and their role in thrombus formation. Antioxid Redox Signal. 2016;24(1):1-15.

45. Pierredon S, Ribaux P, Tille JC, Petignat P, Cohen M. Comparative secretome of ovarian serous carcinoma: gelsolin in the spotlight. Oncol Lett. 2017; 13(6):4965-73.

46. Zunino R, Li Q, Rosé SD, Romero-Benítez MM, Lejen T, Brandan NC, Trifaró JM. Expression of scinderin in megakaryoblastic leukemia cells induces differentiation, maturation, and apoptosis with release of plateletlike particles and inhibits proliferation and tumorigenesis. Blood. 2001;98(7):2210-9.

47. Peña E, Padro T, Molins B, Vilahur G, Badimon L. Proteomic signature of thrombin-activated platelets after in vivo nitric oxide-donor treatment: coordinated inhibition of signaling (phosphatidylinositol 3-kinase-, , 14-3-3ろ, and growth factor receptor-bound protein 2) and cytoskeleton protein translocation. Arterioscler Thromb Vasc Biol. 2011;31(11):2560-9.

48. Saini J, Sharma PK. Clinical, prognostic and therapeutic significance of heat shock proteins in cancer. Curr Drug Targets. 2017; https://doi.org/10.2174/ 1389450118666170823121248.

49. Karmakar S, Banerjee D, Chakrabarti A. Platelet proteomics in thalassemia: factors responsible for hypercoagulation. Proteomics Clin Appl. 2016; 10(3):239-47.

50. Wang YJ, Guo XL, Li SA, Zhao YQ, Liu ZC, et al. Prohibitin is involved in the activated internalization and degradation of protease-activated receptor 1. Biochim Biophys Acta. 2014;1843(7):1393-401.

51. Awasthi N, Schwarz RE. Profile of nintedanib in the treatment of solid tumors: the evidence to date. Onco Targets Ther. 2015;8:3691-701.

52. Tang H, Yao L, Tao X, Yu Y, Chen M, Zhang R, Xu C. miR-9 functions as a tumor suppressor in ovarian serous carcinoma by targeting TLN1. Int J Mol Med. 2013:32(2):381-8.

53. Haslene-Hox H, Oveland E, Woie K, Salvesen HB, Wiig H, Tenstad O. Increased WD-repeat containing protein 1 in interstitial fluid from ovarian carcinomas shown by comparative proteomic analysis of malignant and healthy gynecological tissue. Biochim Biophys Acta. 2013;1834(11):2347-59.

54. Dasgupta SK, Le A, Da Q, Cruz M, Rumbaut RE, Thiagarajan P. Wdr1dependent actin reorganization in platelet activation. PLoS One. 2016; 11(9):e0162897.

\section{Submit your next manuscript to BioMed Central and we will help you at every step:}

- We accept pre-submission inquiries

- Our selector tool helps you to find the most relevant journal

- We provide round the clock customer support

- Convenient online submission

- Thorough peer review

- Inclusion in PubMed and all major indexing services

- Maximum visibility for your research

Submit your manuscript at www.biomedcentral.com/submit

C) Biomed Central 